\section{Cyclophosphamide and Prednisone in Nephrosis}

Sir,

The paper by Drs. Tsao and Yeung (Archives of Disease in Childhood (1971), 46, 327) is, as far as I am aware, the first to describe the use of cyclophosphamide as the primary treatment of the nephrotic syndrome in children. The results they obtained might have been expected since it has already been amply demonstrated that cyclophosphamide induces prolonged remissions in steroid-dependent nephrotic children.

The authors suggest 'using cyclophosphamide in all patients who relapse after a steroid-induced remission'. Some $70-90 \%$ of steroid-sensitive nephrotic children will relapse at least once, and it is questionable whether the recognized immediate risks from haemorrhagic cystitis or inadvertent exposure of non-immunes to varicella or measles, and the uncertain long-term effects on fertility, justify treating such a high proportion of patients with cyclophosphamide.

In a recent controlled trial of azathioprine (Abramowicz et al., 1970) a noteworthy finding was that only $36 \%$ of children fulfilled the definition of 'frequent relapses' and no serious steroid toxicity occurred among them. Such effects were largely a product of the time when prolonged maintenance therapy with corticosteroids was fashionable. There is thus a strong argument for continuing to treat each relapse with a short course of prednisone until evidence of more serious toxicity, e.g. growth retardation, develops.

R. H. R. WHITE

REFERENCE

Abramowicz, M., Barnett, H. L., Edelmann, C. M., Greifer, I., Kobayashi, O., Arneil, G. C., Barron, B. A., Gordillo, G., Hallman, P. N., Tiddens, H. A. (1970). Controlled trial of azathioprine in children with nephrotic syndrome. Lancet, 1 , 952.

\section{Tetracycline in Urinary Tract Infections}

Sir,

The need for 'early recognition of urinary tract infection with renal impairment' in the jaundiced neonate is well shown by $\mathrm{Ng}$ and Rawstron (April 1971). But their plea for prompt antibiotic treatment is spoilt by the fact that they used an inappropriate antibiotic on their infants, all of whom had raised blood urea levels.

Renal impairment at the time of a neonatal urine infection is common. Occasionally it progresses to severe renal failure with complete renal shut down, necessita- ting dialysis. I have seen four such infants in the past 18 months, one of whom did not recover adequate renal function and died.

Therefore, it is most important to avoid the use of any drug for the treatment of neonatal urine infection which may precipitate or exacerbate renal failure. There have been several recent reviews on the use of antibiotics in renal failure (Linton and Lawson, 1970; British Medical Journal, 1971). All agree that tetracycline is dangerous. It is catabolic and may precipitate fatal uraemia (Lew and French, 1966). It should not be used in the presence or likelihood of renal impairment.

Roy Meadow
Department of Paediatrics and
Child Health, The University of Child Health, The Univer
Leeds, Leeds LS1 3ET.

REFERENCES

British Medical fournal (1971). Antibacterial agents in renal failure, 1, 621

Lew, H. T., and French, S. W. (1966). Tetracycline nephrotoxicity and nonoliguric acute renal failure. Archives of Internal Medicine, 118, 123.

Linton, A. L., and Lawson, D. H. (1970). Antibiotic therapy in renal failure. Proceedings of the European Dialysis and Transplant Association, 1, 371.

$\mathrm{Ng}$, S. H., and Rawstron, J. R. (1971). Urinary tract infections presenting with jaundice. Archives of Disease in Childhood, 46, 173.

We showed Dr. Meadow's letter to the authors whose comments were as follows:

Dr. Roy Meadow has justifiably condemned the use of tetracycline in those cases we described. We were aware in 1965 of some of the toxic effects of tetracycline in such cases (Wegienka, and Weller, 1964) and great care had been exercised throughout the management of each infant, taking into account the biochemical effects of the tetracycline group known at that time. Unfortunately, the range of antibiotics in 1965 was also limited, and we were extremely lucky. We do not intend to highlight the administration of tetracycline in our article, and in the light of modern knowledge of the tetracyclines we join hands with Dr. Meadow in condemning their use, not only in situations where the renal or hepatic functions may be compromised, but also in paediatric practice as a whole.

S. H. $\mathrm{Ng}$ and J. Rawstron Department of Child Health, King's College Hospital, London, S.E.5.

REFERENCE

Wegienka, L. C., and Weller, J. M. (1964). Renal tubular acidosis caused by degraded tetracycline. Archives of Internal Medicine, 144, 232. 